\title{
Patterns and Severity of Injuries in Patients Following Road Traffic Accidents - A Medicolegal Aspects.
}

\author{
Archana Chaudhary ${ }^{1}$, Harihar Wasti ${ }^{2}$ \\ ${ }^{1}$ Department of Forensic Medicine, B and C Medical College Teaching Hospital and Research Center, \\ Birtamode, Jhapa, Nepal. \\ ${ }^{2}$ Department of Forensic Medicine, IOM, TUTH, Kathmandu, Nepal.
}

Correspondence:

Dr. Archana Chaudhary, Department of Forensic Medicine, B and C Medical College Teaching Hospital and Research Center, Birtamode, Jhapa.

Email: archiechaudhary@yahoo.com

Phone: +9779801032248

\begin{abstract}
Background and purpose: Road traffic accident (RTA) is the major cause of the morbidity and mortality throughout the world and the incidence is still very high in developed and developing countries. With the objective to see the pattern and severity of the injury following RTA from the medico legal point of view, this study was design in a tertiary care centre at far eastern part of Nepal. Material and method: This is a prospective analytical study with non- probability consecutive sampling of road traffic accidents cases presented in the emergency department during period of 6 months. Type of study: Prospective Analytical study. Result: There were total 210 cases of road traffic accidents with mean age of 31.8 (SD 15.7) years where majority were at 20-29 years of age group and males were the majority. Majority of the cases had injuries to the extremities followed by head. Grievous injury and life threatening injuries were also a common finding in this study. Conclusion: Road traffic accidents are more common among male, bike/scooter rider and 22-29 years of age group. Majority of the injury were fracture/dislocation of extremities and intracranial injuries. As per the medicolegal aspect, grievous and life threatening injuries were common findings among patients with road traffic accidents.
\end{abstract}

Key words: medicolegal, grievous, road traffic accident, automobile accidents, head injury.

$\mathrm{R}$ oad traffic accident (RTA) is the major cause of the morbidity and mortality still very high in developed and developing countries. ${ }^{1-4}$ Among different type of the RTA, motorcycle accidents holds the number one cause of accident in most of the country. ${ }^{5-7}$ Majority of morbidity/mortality are due to injuries to the limbs, head, abdomen, chest and spine as mention in different literature. ${ }^{1-7}$ With the objective to see the pattern and severity of the injury following RTA from the medico legal point of view, this study was design in a tertiary care centre at far eastern part of Nepal.

\section{Material and Methods}

Type of study: Prospective Analytical study Sampling technique: Non- probability consecutive sampling

Sample size: 210 patients

Duration of study: 6 month

Site of study: B\&C Medical College Teaching

Hospital and Research Centre

13

Date submitted: 8/ 11/2019

Date accepted: 3/12/2019

\section{Inclusion criteria:}

All the trauma patients presented to the emergency department (ER) at the site of study.

\section{Exclusion criteria}

Trauma not related to Road Traffic Accident like physical assault, accidental fall, and accidental injury by falling objects.

All the patients who were brought dead or died before detail evaluations were completed.

\section{Data collection and analysis:}

All the patients who meet the inclusion criteria were collected in performed proforma. Age, gender, different categories of RTA, site of external injury, types of internal injury severity of injury and management strategies were collected in those proforma. 


\section{Results}

During study period total 310 cases presented to our emergency department, among them 210 cases were of RTA. The mean age of these patients with road traffic accidents was 31.8 (SD 15.7) years where majority were at 20-29 years of age group (Figure 1). There were $74 \%$ male patients who encountered road traffic accidents (Figure 2).

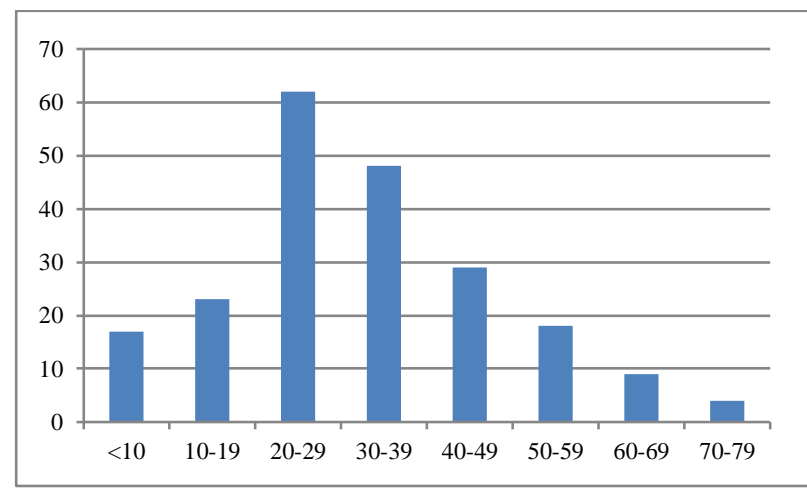

Figure 1: Distribution of patients in different age categories.

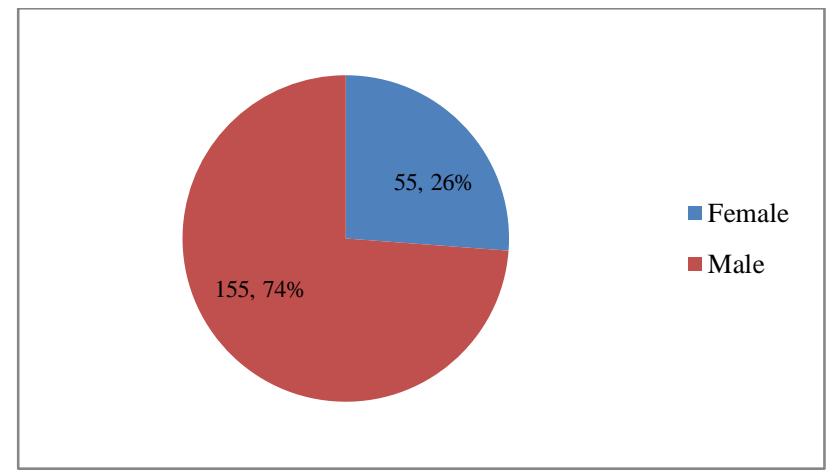

Figure 2: Distribution of gender among patients with RTA.

Among the patients with RTA, majority were the rider of motorbike/ scooter $(44.8 \%)$ followed by the pedestrian (30\%) (Figure 3).Evidence of external injuries among those patients were more on the extremities $(48 \%)$ followed by head and face (39\%) (Figure 4). However, all the external injuries were not associated with major internal injuries $(58.1 \%)$ (Table 1). Though majority didn't have internal injuries, there were significant number of patients who had obvious internal injuries. Among all the patients, $18.1 \%$ of patients had isolated fracture/ dislocation of the bones of limbs, $10.5 \%$ had head injuries with significant CT findings, and
$4.8 \%$ were cases of polytrauma whose more than one type of body parts were injured on further imaging (Table 1).

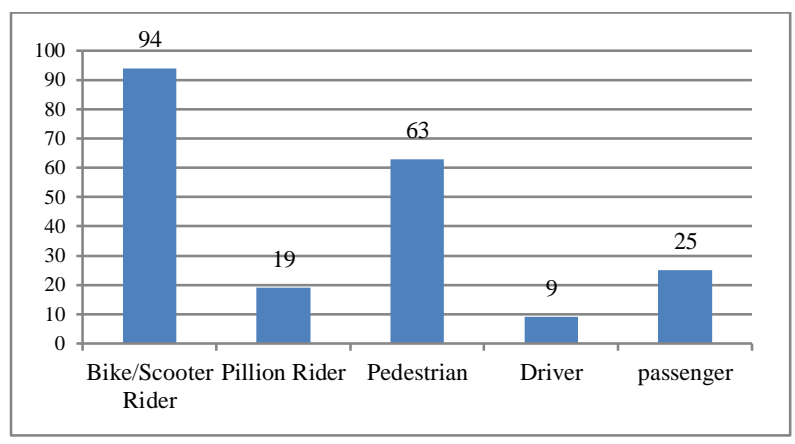

Figure 3: Distribution of different categories of RTA.

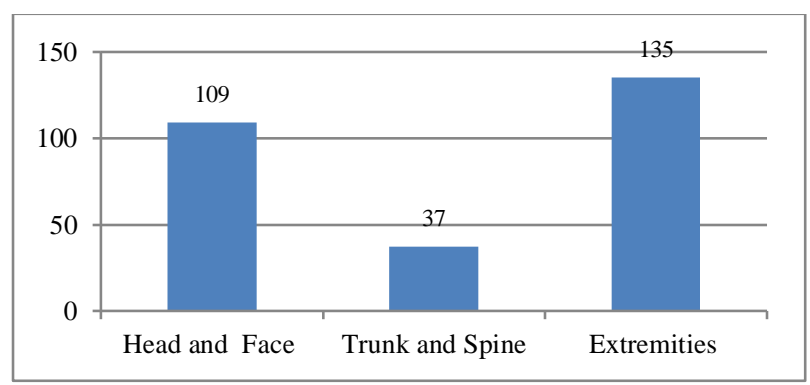

Figure 4: Evidence of external injuries in patients with RTA

Table 1: Evidence of internal injuries in patients with RTA

\begin{tabular}{lll}
\hline Categories of internal injuries & $\begin{array}{l}\text { Frequenc } \\
\mathbf{y}\end{array}$ & Percent \\
\hline No internal injuries & 122 & 58.1 \\
Intracranial injuries & 22 & 10.5 \\
Facial injuries & 4 & 1.9 \\
Chest injuries & 5 & 2.4 \\
Abdominal/ retroperitoneal/ & 9 & 4.3 \\
Pelvic/ spine injuries & & \\
Fracture/ dislocation of limbs & 38 & 18.1 \\
Polytrauma & 10 & 4.8 \\
\hline Total & $\mathbf{2 1 0}$ & $\mathbf{1 0 0 . 0}$ \\
\hline
\end{tabular}

Among the different type of bony injuries found in the patients following RTA, majority were tibia/fibula fracture followed by radius/ulna fracture/ dislocation (Figure 5). Among patients with head injuries contusions were seen in majority of cases followed by isolated skull fracture without parenchymal injury (Figure 6).Diffuse axonal injury, extra dural hematoma, traumatic subarachnoid hemorrhage, sub-dural hemorrhage were also seen in significant number of the patients (Figure 6). Spinal injuries which include Cervical 
to lumbosacral spine were also the major finding in these RTA patients (Figure.7).

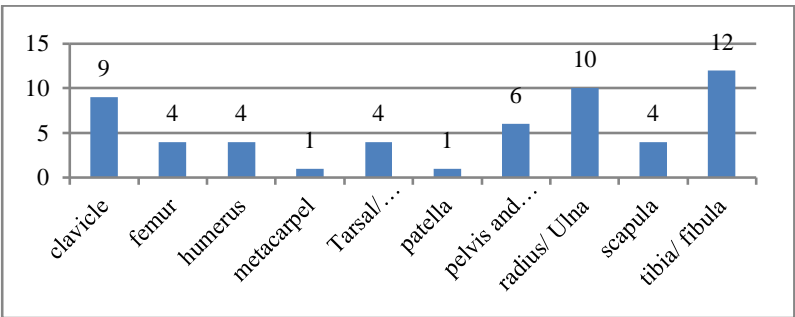

Figure 5: Frequencies of different bones fractured/ dislocated during RTA.

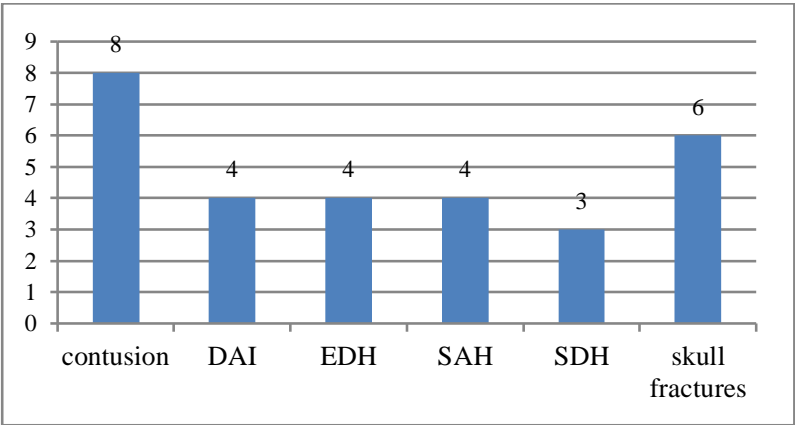

Figure 6: Frequencies of different types of head injuries as evident in CT scan.

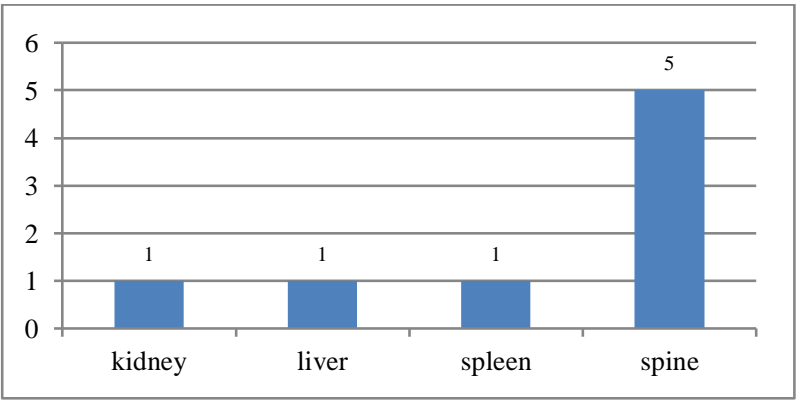

Figure 7: Frequencies of different types of abdominal and spinal injuries

Medicolegally all these patients were grouped into simple, grievous, life threatening, grievous and life threatening. Although majority (57.1\%) of the patients had simple injury there were significant number of the patients who had other types of injury, among those patients with significant

egneuro Volume 02, Issue 01, 2020 finding $27.6 \%$ falls into grievous category followed by $13.3 \%$ into life threatening category (Table 2 )

Table 2: Severity of injuries as per medicolegal aspect.

\begin{tabular}{lll}
\hline Types of Injuries & Frequency & Percent \\
\hline Grievous & 58 & 27.6 \\
$\begin{array}{l}\text { Grievous and life } \\
\text { threatening }\end{array}$ & 4 & 1.9 \\
$\begin{array}{l}\text { Life threatening } \\
\text { Simple }\end{array}$ & 28 & 13.3 \\
\hline Total & 120 & 57.1 \\
\hline
\end{tabular}

Among these patients, $17.6 \%$ of them refused further treatment and was taken to other centre/home depending upon their nature of internal injuries. At the site of the study $29.5 \%$ underwent operative procedure and remaining $52.9 \%$ were managed conservatively (Table 3 ).

Table 3: Various management strategies done for patients with RTA.

\begin{tabular}{lll}
\hline Management & Frequency & Percent \\
\hline Conservative & 111 & 52.9 \\
Opertive & 62 & 29.5 \\
Refused treatement & 37 & 17.6 \\
\hline Total & 210 & 100.0 \\
\hline
\end{tabular}

Association of age and gender with different category of RTA showed high significance with $\mathrm{p}$ value $<0.01$ (Table 4 and 5). This association showed male and young patients are high prone to RTA if they are the riders. However, there was no significant association of age, gender, category of the RTA with the severity of injury in this study which was done using Chi Square test.

\section{Discussion}

Road traffic accident seems to be epidemic in majority of developing and develop countries among the youngsters. ${ }^{1,2,4}$ As mention in the literature from Kuwait, Malaysia and western Nepal these accident are harming people between 20 to 29 years of age, which seems same as well Eastern part of Nepal. ${ }^{2-4}$ 
Table 4: Association of age and different category of RTA.

\begin{tabular}{ccccccc}
\hline Age Category & $\begin{array}{c}\text { Bike/Scooter } \\
\text { Rider }\end{array}$ & Pillion Rider & Pediastrian & Driver & passenger & P Value \\
\hline$<10$ & 0 & 2 & 13 & 2 & 0 & 6 \\
$10-19$ & 7 & 1 & 9 & 0 & 10 & 0.000 \\
$20-29$ & 31 & 8 & 12 & 2 & 3 & 1 \\
$30-39$ & 29 & 5 & 7 & 2 & 0 & \\
$40-49$ & 14 & 2 & 8 & 0 & 1 & 0 \\
$50-59$ & 11 & 0 & 6 & 5 & 1 & 25 \\
$60-69$ & 2 & 1 & 3 & 9 & \\
$70-79$ & 0 & 0 & 63 & & \\
\hline Total & 94 & 19 & &
\end{tabular}

Table 5: Asssociaton of gender and different category of RTA.

\begin{tabular}{|c|c|c|c|c|c|c|}
\hline Gender & $\begin{array}{c}\text { Bike/Scooter } \\
\text { Rider }\end{array}$ & $\begin{array}{l}\text { Pillion } \\
\text { Rider }\end{array}$ & Pediastrian & Driver & passenger & P Value \\
\hline Female & 12 & 10 & 20 & 5 & 8 & \multirow{2}{*}{0.000} \\
\hline Male & 82 & 9 & 43 & 4 & 17 & \\
\hline Total & 94 & 19 & 63 & 9 & 25 & \\
\hline
\end{tabular}

Involvement of the young boys in RTA could also affect the overall burden to the society and development of the country. ${ }^{6,10,11}$ In this study second most common people victimized by the RTA are the pedestrian, which might be due to lack of proper walking lane in this part of Nepal. Injuries to the extremities, especially of Tibia/Fibula seem to be major cause of disability abstaining them from routine activities. In other parts of the world orthopedic injury are still the major causes of disability following RTA. ${ }^{12}$

Traumatic brain injury are also one of the major cause of mortality and morbidity following RTA. ${ }^{12,13,14}$ This type of injury not only makes people bed ridden but also significant affect the behavior, memory, relationship and show on. ${ }^{15-18}$ In this study Head injury seems to be the second most common type of injuries following RTA. contusions, DAI, traumatic SAH, SDH, EDH are the worse type of the injuries one can imagine in their lifetime because they are life threatening and severely affects the quality of life among survivors. ${ }^{15,16}$ These type of injury are also in significant proportion in this study.

According to Muluki Criminal Code 2074 , injuries are classified as simple and grievous or angabhanga. The following enlisted are grievous injuries. ${ }^{19}$

a. privation of the sight of either eye,

b. privation of smelling power of nose,

c. privation of hearing power of either ear,

d.privation of speaking power of the tongue,

e. cutting of woman's breast

f. emasculation of man and woman ( making woman infertile or man impotent.

g. privation of the backbone, hand, leg, or joint of such organ by breaking, fracturing dislocating it.

h. any injury which cause the sufferer to be unable to perform his/ her professional work.

The existing legal provisions addressing injuries in Nepal look neither scientific nor practical. There should be amendment in number of conditions of angabhanga. All the fractures and dislocations leading disabilities of any bone or joint of any body part should come under angabhanga and any injury endangering life or life threatening injury also should be added in this section.

\section{Conclusion}

Road traffic accidents are more common among male, bike/scooter driver and 22-29 years of age group. Majority of the major injury were fracture/dislocation of extremities and intracranial

egneuro, Volume 02, Issue 01, 2020 
injuries. As per the medicolegal aspect, grievous and life threatening injuries are common findings among patients with road traffic accidents.

\section{References}

1. 1.Beck LF, Dellinger AM, O'neil ME. Motor vehicle crash injury rates by mode of travel, United States: using exposure-based methods to quantify differences. American Journal of Epidemiology. 2007 Apr 21;166(2):212-8.

2. 2.Al-Kandary N, Al-Waheeb S. Patterns of accidental deaths in Kuwait: a retrospective descriptive study from 2003-2009. BMC public health. 2015 Dec;15(1):302.

3. 3.Sharifah Allyana SM, Zarir HZ, Abdul Rahmat AM, Siti Atiqah MF, Noor FP, Wong SV, Jamilah MJ. Recent trend of fatal motorcycle crashes in Malaysia. InProceedings of the 8th International Forum of Automotive Traffic Safety (INFATS) 2010 Dec.

9. 9.Wagenaar AC. Effects of macroeconomic conditions on the incidence of motor vehicle accidents. Accident Analysis \& Prevention. 1984 Jun 1;16(3):191-205.

10. 10.Hoang HT, Pham TL, Vo TT, Nguyen PK, Doran $\mathrm{CM}$, Hill PS. The costs of traumatic brain injury due to motorcycle accidents in Hanoi, Vietnam. Cost Effectiveness and Resource Allocation. 2008 Dec;6(1):17.

11. 11.Bastida JL, Aguilar PS, González BD. The economic costs of traffic accidents in Spain. Journal of Trauma and Acute Care Surgery. 2004 Apr $1 ; 56(4): 883-9$.

12. 12.Gorski TF, Gorski YC, McLeod G, Suh D. Patterns of injury and outcomes associated with motocross accidents. The American Surgeon. 2003 Oct 1;69(10):895.

13. 13.Roozenbeek B, Maas AI, Menon DK. Changing patterns in the epidemiology of traumatic brain injury. Nature Reviews Neurology. 2013 Apr;9(4):231.

14. 14.Andersson EH, Björklund R, Emanuelson I, Stålhammar D. Epidemiology of traumatic brain injury: a population based study in western Sweden. Acta neurologica scandinavica. 2003 Apr;107(4):256-9.
4. 4.Mishra B, Sinha ND, Sukhla SK, Sinha AK. Epidemiological study of road traffic accident cases from Western Nepal. Indian journal of community medicine: official publication of Indian Association of Preventive \& Social Medicine. 2010 Jan;35(1):115.

5. 5.Hoang HT, Pham TL, Vo TT, Nguyen PK, Doran CM, Hill PS. The costs of traumatic brain injury due to motorcycle accidents in Hanoi, Vietnam. Cost Effectiveness and Resource Allocation. 2008 Dec;6(1):17.

6. 6.Kudebong M, Wurapa F, Nonvignon J, Norman I, Awoonor-Williams JK, Aikins M. Economic burden of motorcycle accidents in Northern Ghana. Ghana medical journal. 2011;45(4).

7. 7.Williams MJ, Hoffmann ER. Motorcycle conspicuity and traffic accidents. Accident Analysis \& Prevention. 1979 Sep 1;11(3):209-24.

8. 8.McKinlay A, Grace RC, Horwood LJ, Fergusson DM, Ridder EM, MacFarlane MR. Prevalence of traumatic brain injury among children, adolescents and young adults: prospective evidence from a birth cohort. Brain injury. 2008 Jan 1;22(2):175-81.

15. 15.Ashman TA, Gordon WA, Cantor JB, Hibbard MR. Neurobehavioral consequences of traumatic brain injury. Mount Sinai Journal of Medicine. 2006 Nov 1;73(7):999-1005.

16. 16.Vanier, M., Mazaux, J.M., Lambert, J., Dassa, C. and Levin, H.S., 2000. Assessment of neuropsychologic impairments after head injury: interrater reliability and factorial and criterion validity of the Neurobehavioral Rating ScaleRevised. Archives of Physical Medicine and Rehabilitation, 81(6), pp.796-806.

17. 17.Matsuoka $Y$, Nishi D, Nakajima S, Kim Y, Homma M, Otomo Y. Incidence and prediction of psychiatric morbidity after a motor vehicle accident in Japan: The Tachikawa Cohort of Motor Vehicle Accident Study. Critical care medicine. 2008 Jan 1;36(1):74-80.

18. 18.Hickling EJ, Gillen R, Blanchard EB, Buckley T, Taylor A. Traumatic brain injury and posttraumatic stress disorder: a preliminary investigation of neuropsychological test results in PTSD secondary to motor vehicle accidents. Brain Injury. 1998 Jan 1;12(4):265-74.

19. Offences Relating to Hurt and Grievous Hurt. The national penal code act 2017 of Nepal.2017: 122-7. 